\title{
CONTRIBUIÇÕES DO GEOGEBRA PARA O ENSINO DE GEOMETRIA NO ENSINO
} FUNDAMENTAL II

\section{GEOGEBRA CONTRIBUTIONS TO GEOMETRY TEACHING IN FUNDAMENTAL EDUCATION II}

\section{CONTRIBUCIONES DE GEOGEBRA A LA ENSEÑANZA DE GEOMETRÍA EN LA EDUCACIÓN FUNDAMENTAL II}

Maria da Conceição Siqueira de Souza ${ }^{1}$

José Luiz Cavalcante ${ }^{2}$

1. Mestre. Professora da Rede Estadual de Ensino do Estado de Pernambuco.

2. Doutor. Professor da Universidade Estadual da Paraíba.

\begin{abstract}
RESUMO: Esta pesquisa teve como propósito refletir sobre o ensino de geometria a partir do uso de softwares geométricos na sala de aula com alunos do Ensino Fundamental da Escola Estadual Quilombola Vereadora Alzira Tenório do Amaral (EEQVATA), buscando despertar o interesse pela Geometria. Trabalhou-se com a hipótese que a utilização do GeoGebra instiga a curiosidade dos alunos, permitindo que os mesmos se aproximem da geometria de forma dinâmica e prazerosa. A pesquisa teve uma abordagem qualitativa, na modalidade de campo. A amostra foi composta pelos alunos do $9^{\circ}$ ano do Ensino Fundamental. $\mathrm{Na}$ metodologia seguiu- se quatro passos: aplicação de atividade para levantamento do conhecimento prévio; atividades com uso do GeoGebra no laboratório de informática; aplicações de atividades após o uso do GeoGebra que funcionou como um elemento avaliativo da utilização da ferramenta interativa e, por último, um questionário com 10 itens para ser respondido pelos alunos sobre o uso da tecnologia e do software GeoGebra nas aulas. O GeoGebra se revelou uma ferramenta metodológica dinâmica e interativa que proporcionou ao professor uma forma a mais de explorar os conteúdos, despertando a curiosidade e o interesse dos alunos, além de possibilitar um momento de interação aluno-professorconteúdo.
\end{abstract}

Palavras-chave: Softwares Educacionais. GeoGebra. Ensino de Geometria.

\begin{abstract}
The purpose of this research was to reflect on the teaching of geometry from the use of geometric software in the classroom with elementary school students at the Quilombola Vereadora State School Alzira Tenório do Amaral (EEQVATA), seeking to arouse interest in Geometry. We worked with the hypothesis that the use of GeoGebra instigates students' curiosity, allowing them to approach geometry in a dynamic and pleasurable way. The research had a qualitative approach, in the field modality. The sample was composed by 9th grade students. In the methodology, four steps were followed: application of activity to survey previous knowledge; activities using GeoGebra in the computer lab; applications of activities after the use of GeoGebra that functioned as an evaluative element of the use of the interactive tool and, finally, a questionnaire with 10 items to be answered by the students on the use of technology and the GeoGebra software in classes. GeoGebra proved to be a dynamic and interactive methodological tool that provided the teacher with an additional way to explore the contents, arousing the students' curiosity and interest, in addition to allowing a moment of student-teacher-content interaction.
\end{abstract}

Keywords: Educational Softwares. GeoGebra. Geometry Teaching.
RESÚMEN: El propósito de esta investigación fue reflexionar sobre la enseñanza de la geometría a partir del uso de software geométrico en el aula con estudiantes de primaria de la Escuela Estatal Quilombola Vereadora Alzira Tenório do Amaral (EEQVATA), buscando despertar interés en la Geometría. Trabajamos con la hipótesis de que el uso de GeoGebra instiga la curiosidad de los estudiantes, permitiéndoles acercarse a la geometría de una manera dinámica y agradable. La investigación tuvo un enfoque cualitativo, en la modalidad de campo. La muestra fue compuesta por estudiantes de noveno grado. En la metodología, se siguieron cuatro pasos: aplicación de la actividad para encuestar conocimientos previos; actividades usando GeoGebra en el laboratorio de computación; aplicaciones de actividades después del uso de GeoGebra que funcionó como un elemento evaluativo del uso de la herramienta interactiva $\mathrm{y}$, finalmente, un cuestionario con 10 ítems para ser respondidos por los estudiantes sobre el uso de la tecnología y el software GeoGebra en las clases. GeoGebra demostró ser una herramienta metodológica dinámica e interactiva que proporcionó al maestro una forma adicional de explorar los contenidos, despertando la curiosidad e interés de los estudiantes, además de permitir un momento de interacción estudiantemaestro-contenido.

Palabras clave: Software educativo GeoGebra. Enseñanza de geometría. 


\section{Introdução}

A sociedade contemporânea na qual estamos inseridos faz uso da matemática cotidianamente, não somente hoje como em todos os tempos. É uma ferramenta que o homem conta para intervir socialmente. O que se parece é que muitas das escolas não associam matemática com realidade, deixando esta, reduzida a uma simples disciplina de preceitos teóricos repassados pelos velhos livros didáticos. O aluno, a escola e os sujeitos sociais como um todo estão inseridos na era digital, diante desse cenário, o ensino da matemática pode caminhar junto com a tecnologia. De acordo com os Parâmetros Curriculares Nacionais (PCN):

A utilização dos computadores na educação possibilita a criação de ambiente de aprendizagem em que os alunos possam pesquisar, fazer antecipações e simulações, confirmar ideias prévias, experimentar, criar soluções construir novas formas de representação mental. (BRASIL, 1998, p. 141).

Com a inserção da tecnologia nas práticas sociais, muitos professores procuram inovar seus recursos didáticos e tentam resgatar o interesse dos alunos pela matemática. Nesse sentido, percebemos a necessidade de unir as Tecnologias de Informação e Comunicação (TIC) ao ambiente escolar. Conforme Belfort (2002) em particular, na matemática, as TIC podem favorecer a compreensão de conceitos, o desempenho na resolução de problemas e o desenvolvimento do raciocínio lógico- dedutivo do aluno.

Segundo De Oliveira (2001), estes softwares estão inseridos em duas categorias básicas: os softwares aplicativos que não foram criados para fins educativos, mas podem ser utilizados para tal; e os softwares educativos que são construídos especificamente para obtenção de conhecimentos e favorecimento do ensino e aprendizagem dos conteúdos didáticos e uma ferramenta pedagógica para o professor de criação e construção.

Já Souza (2011), afirma que para os professores esses softwares educacionais, principalmente os softwares geométricos, vêm com o propósito de darem-lhes a oportunidade de levar para a sala de aula uma ferramenta que permite ao aluno obter a compreensão e resolução de problemas com as visualizações, análise e dedução e rigor dos problemas propostos.

É importante que os softwares educacionais não se tornem programas apenas instalados obrigatoriamente nos laboratórios das escolas, eles precisam ser usados de forma integrada aos conteúdos escolares de forma a facilitar a apreensão dos mesmos. Este trabalho, como afirma Costa e Oliveira (2004), desperta no aluno o interesse de construir e ampliar seu conhecimento, fazendo parte de sua bagagem educacional e os mesmos saiam do ambiente escolar de forma que possa ser proveitoso em seu cotidiano. 
O uso de softwares na Matemática desperta nos alunos um interesse maior em resolver e criar problemas, despertando a curiosidade pelo conhecimento científico e mostra o lado dinâmico dos softwares. Permite a manipulação de figuras espaciais e planas em todas as dimensões, sendo uma visualização detalhada quando comparado com as atividades propostas no quadro negro ou no papel. Quando usado, os softwares educacionais amenizam as dificuldades em compreender, entender e resolver problemas propostos em geometria.

Ao observar em certos espaços escolares a inutilização dos seus laboratórios de informática, esquecendo-se de utilizá-los nos fazeres pedagógicos, e o baixo desempenho dos alunos nas avaliações externas, principalmente quando se trata de conhecimentos geométricos, sentimos a necessidade de intervir nestas realidades, que também é verificada na EEQVATA, buscando analisar quais contribuições podem ser dadas ao ensino de geometria a partir do uso do software GeoGebra em aulas de matemática. Sabendo que contamos, hoje, com os mais diversos avanços tecnológicos de acesso fácil, vimos nestes uma possibilidade de aliar educação e tecnologia de modo que fosse possível propiciar aulas mais compatíveis com as necessidades e demandas dos alunos.

Então, pretendemos trazer este recurso para as aulas de matemática a fim de contribuir para o ensino e a aprendizagem e, assim, poder sair de modelos prontos e acabados para produzir e resolver os problemas que são propostos de modo mais satisfatório.

Partindo do caráter intervencionista desta pesquisa, temos como objetivo geral refletir sobre o ensino de geometria, a partir do uso de softwares geométricos na sala de aula do Ensino Fundamental II, a fim de reconhecer quais práticas são desenvolvidas no que se refere ao ensino de Geometria.

Para alcançarmos este propósito se faz pertinente identificar as práticas vinculadas ao ensino de geometria no interior das escolas. A partir da identificação nos propomos realizar atividades a partir de softwares geométricos, neste caso o GeoGebra, visando apresentar práticas alternativas em espaços escolares; analisar o uso dos softwares nas atividades de geometria; e assim, observar a participação, o interesse e o comportamento dos alunos durante a utilização dos softwares de geometria nas aulas.

\section{Material e Métodos}

Este estudo foi realizado tomando por base metodológica a pesquisa de campo qualitativa e pesquisa bibliográfica para embasamento teórico. Obtivemos os dados a partir da observação dos participantes e da intervenção frente à problemática abordada com a utilização do programa de Geometria Dinâmica (GD), o GeoGebra. É uma pesquisa que parte da nossa experiência 
profissional na escola onde atuamos como professora, o que caracteriza como um estudo de caso. Segundo Alves-Mazzotti (2006), o estudo do caso parte do propósito do essencial que faz parte de alguém, o coletivo e instrumental que tem como objetivo estudar uma teoria ou hipótese testada, utilizado de diferentes técnicas e recursos para coleta de dados em que há interação entre o pesquisador e o pesquisado.

A abordagem metodológica selecionada para o estudo em questão é baseada no aspecto qualitativo, pautado na participação, interesse e resolução dos problemas propostos. Os sujeitos são alunos do ensino fundamental dos anos finais. A escolha da instituição pesquisada aconteceu em virtude de ser a primeira escola quilombola da cidade e por estar localizada na zona rural e ser considerada uma escola de difícil acesso para muitos professores e alunos.

A presente pesquisa foi realizada na Escola Estadual Quilombola Vereadora Alzira Tenório do Amaral - EEQVATA, localizada na Comunidade Quilombola de Buenos Aires de Quintibu na cidade de Custódia-PE, zona rural, distante $14 \mathrm{~km}$ da cidade. Esta escola foi inaugurada em 2012 e possui 19 anexos distribuídos em comunidades vizinhas, comportando uma turma cada anexo.

A instituição funciona nos três períodos. Durante a manhã, o Ensino Fundamental II, turmas $6^{\circ}$ ao $8^{\circ}$ ano, e Ensino Jovens e Adultos (EJA) Fundamental II, somando 171 alunos. Período da tarde: Ensino Fundamental II $8^{\circ}$ ao $9^{\circ}$ ano, EJA Fundamental II, Ensino Médio e Ensino Normal Médio, somando 308 alunos. No período noturno são turmas de EJA Médio, Travessia Médio e Ensino Normal Médio com 54 alunos. Há 21 professores.

A escola tem 19 anexos, como dito anteriormente, funcionando com as modalidades de ensino: Saberes da Terra, tarde e noite, EJA do Campo Médio, tarde e noite, estão localizadas escolas das comunidades quilombola vizinhas. Possui: 402 alunos, 45 professores.

A amostra de estudo foi constituída com 34 alunos o $9^{\circ}$ ano do Ensino Fundamental, destes 25 eram do gênero feminino e 9 masculino, com faixa etária entre 14 a15 anos. A seleção para a escolha dos participantes dessa pesquisa se deu com base no objetivo de refletir o processo de ensino-aprendizagem em geometria dos mesmos, por serem alunos dos anos finais do ensino fundamental II, turma de uma escola quilombola que atende a um público diferenciado, e por serem eles que participam do processo de avaliação Prova Brasil e Sistema de Avaliação de Pernambuco (SAEPE, 2013).

A utilização de Tecnologias Informacionais e Comunicacionais no processo de ensino e aprendizagem da Matemática, especificamente com a GD através do software GeoGebra, vem como uma renovação da prática pedagógica do professor e como uma ferramenta didática que pode facilitar o processo de aprendizagem dos alunos. 
Este software GeoGebra é indicado nas orientações para o ensino de geometria pelos Parâmetros para Educação Básica do Estado de Pernambuco: parâmetros na sala de aula matemática ensino fundamental e médio. Segundo os Parâmetros para Educação Básica do Estado de Pernambuco (2013) "O uso do software GeoGebra pode ser retomado para o estudo dos elementos da circunferência e do círculo, em articulação com o estudo de propriedades e um importante aliado do estudante na realização das construções geométricas".

A sequência metodológica empregada nessa pesquisa foi dividida em quatro momentos: levantamento do conhecimento prévio; atividades com uso do GeoGebra no laboratório de informática; atividades pós uso do GeoGebra, que funcionou como um elemento avaliativo da utilização da ferramenta interativa; e para complementar aplicação de um questionário com 10 itens sobre as aulas de matemática, a tecnologia, o software, em especial o GeoGebra.

\section{Resultados e Discussão}

\section{Resultado do levantamento do conhecimento prévio}

Realizou-se uma análise de cada atividade vivenciada com os alunos do $9^{\circ}$ ano da escola onde atuamos, mas nesta seção traremos a análise do primeiro momento da intervenção. Como frisado anteriormente, antes foi realizada uma avaliação diagnóstica para investigarmos o conhecimento prévio dos educandos em relação ao conteúdo ministrado, momento no qual obtivemos o resultado estruturado na Figura 1.

Figura 1. Conhecimento prévio dos alunos em relação ao conteúdo ministrado.

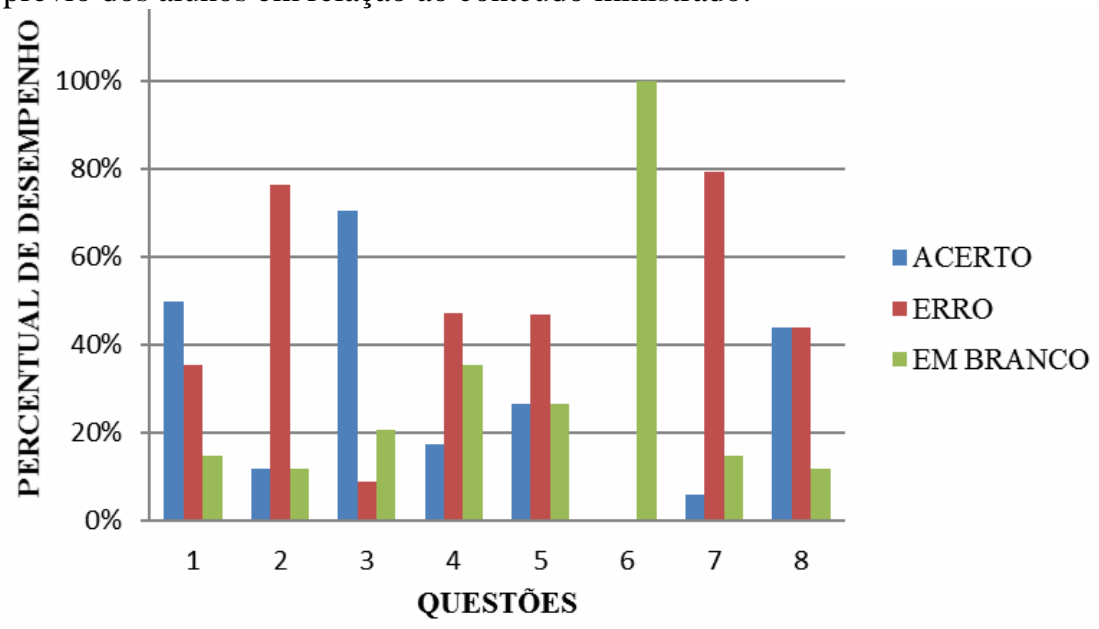

De acordo com a Figura 1, podemos perceber que nas questões 1, 2 e 3, as quais abordam pontos notáveis de um triângulo, o percentual de acerto foi significativo nas questões 1 e 3 , enquanto que na $2^{\mathrm{a}}$ questão foi de $12 \%$ o índice de acertos e $77 \%$ o índice de erros. As questões 
citadas também foram deixadas em branco por alguns alunos. A $3^{\text {a }}$ questão apresenta uma quantidade maior de acerto uma vez comparada com as demais.

Ainda na Figura 1, a questão 4 corresponde ao estudo de semelhança de triângulo, na qual podemos observar que o número de erros foi maior que o número de acertos, e $35 \%$ dos alunos a deixaram em branco. Esse resultado nos dá o indicativo de que esses alunos apresentaram dificuldades em resolver os problemas que envolviam figuras geométricas.

No mesmo Figura, a questão 5 abordou o conteúdo de relação métrica no triângulo, a qual para ser resolvida era necessário aplicar o Teorema de Pitágoras. Nela, o número de acerto é semelhante ao número de questões em branco, tendo um percentual de erro de $47 \%$, correspondendo quase à metade dos alunos.

Na questão 6 o conteúdo abordado foi razões trigonométricas e a expectativa desejada para esse problema não foi correspondida por nenhum dos alunos, que perfizeram 100\% da questão em branco.

Já a questão 7 partiu de um problema que envolve perímetro de figura em malha quadriculada na qual só a observação da mesma sem a compreensão do texto não leva a resolução correta, assim 79\% dos alunos erraram, $6 \%$ acertaram e 15\% deixaram em branco.

Pode-se concluir que na questão número 8 , a quantidade de acertos foi igual ao índice de erros, pois ambos atingiram um percentual de $44 \%$. Nesse universo, apenas $12 \%$ dos alunos não responderam esta questão, que foi elaborada a partir do conteúdo de área de figuras planas.

De maneira geral, os alunos que participaram desta pesquisa, no primeiro diagnóstico, apresentaram dificuldades em relação à interpretação e à resolução das questões abordadas. Com base nestes resultados, iniciaram-se as atividades com uso dos softwares no laboratório de informática, pois, consoante com Albuquerque e Santos (2008, p. 13), as dificuldades em aprender Geometria Plana advêm "em parte à dificuldade de visualizar conceitos e propriedades. Com o surgimento dos Programas de Geometria Dinâmica, esta dificuldade será amenizada, uma vez que os mesmos podem ser comparados ou vistos como materiais concretos virtuais".

\section{Resultado da intervenção com o software GeoGebra}

Segundo os PCN's (1998, p. 37) a reprodução de atividades tem se tornado uma "prática de ensino que tem se mostrado ineficaz, pois a reprodução correta pode ser apenas uma simples indicação de que o aluno aprendeu a reproduzir alguns procedimentos mecânicos, mas não aprendeu o conteúdo e não sabe utilizá-lo em outro contexto”. Já Soares (2009), utilizando o argumento dos alunos, diz que transcrever o que se está nos livros é fácil, difícil é entender os significados e saber 
como utilizá-los. Para que essas dificuldades sejam superadas deve haver mudanças nas metodologias usadas por muitos professores. Continuam os PCN's (1998, p. 39) afirmando que “essa aprendizagem só será possível à medida que o professor proporcionar um ambiente de trabalho que estimule o aluno a criar, comparar, discutir, rever, e perguntar e ampliar ideias".

Uma dessas ferramentas que pode ser utilizada é o uso da tecnologia como o laboratório de informática em que os alunos, em número considerável, se apresentam curiosos e preocupados para assistir as aulas de matemática. Isto se deu, principalmente, pelo fato da maioria não ter muito acesso a este ambiente como também a pouca habilidade para manusear o computador ou por nunca o ter feito ver, ao realizar atividades no laboratório, uma possibilidade de superá-las ou mesmo de vir a fazê-la. Como defende Bolgheroni e Silveira (2008, p. 286) "O uso de ferramentas computacionais aparece aqui como uma possibilidade para modificar esta situação". Então, decidimos trabalhar com a turma em duplas para que ocorresse uma ajuda recíproca.

No laboratório as questões trabalhadas anteriormente no levantamento do conhecimento prévio por meio do uso do software GeoGebra foi discutida e realizada em cinco atividades como: atividade 1 - pontos notáveis do triângulo; atividade 2 - semelhança de figuras e de triângulos, atividade 3 - relação métrica no triângulo retângulo, atividade 4 - razões trigonométricas no triângulo retângulo, atividade 5 - perímetro e área.

O interesse e a participação em resolver as atividades, mesmo obtendo erros, não foi um obstáculo para os alunos continuarem realizando os desafios propostos. Seu entusiasmo foi percebido pela busca constante em encontrar o resultado desejado e o GeoGebra facilitou o entendimento, justificando as respostas encontradas através das imagens. Nesse sentido, o aluno não só pensou o processo de resolução dos problemas, como visualizou seus resultados nos gráficos do programa. De acordo com os PCN's (1998, p. 44) o uso de tecnologia "permite que os alunos construam uma visão mais completa da verdadeira natureza de atividade matemática e desenvolvam atitudes positivas diante de seu estudo", e que o mesmo pode ser usado como "fonte de informação, poderoso recurso para alimentar o processo de ensino aprendizagem”.

\section{Análise: levantamento do conhecimento prévio $\mathrm{X}$ atividades pós-uso do software GeoGebra}

Para analisar se realmente os conceitos de geometria foram apreendidos, compreendemos ser necessária uma avaliação, que chamamos de atividade pós-uso do GeoGebra, com questões semelhantes ao levantamento do conhecimento prévio e na mesma sequência para comparar os resultados e analisar os acertos, erros e questões que ficaram em branco e, com isso, verificar se os efeitos foram positivos ou negativos. 
Examinado a Figura 2, podemos observar que a quantidade de erros e questões em branco teve uma mudança significativa após o uso do GeoGebra. Percebemos que o uso do software na sala de aula aumentou o quantitativo de acertos. Segundo Sá e Juca (2014), quando há um aumento de acertos, isso nos dá indicativos de que as dificuldades encontradas no levantamento foram compreendidas e que as atividades desenvolvidas contribuíram para a aprendizagem de conceitos ainda não assimilados anteriormente.

Figura 2. Apreensão dos conteúdos ministrados a partir do GeoGebra.

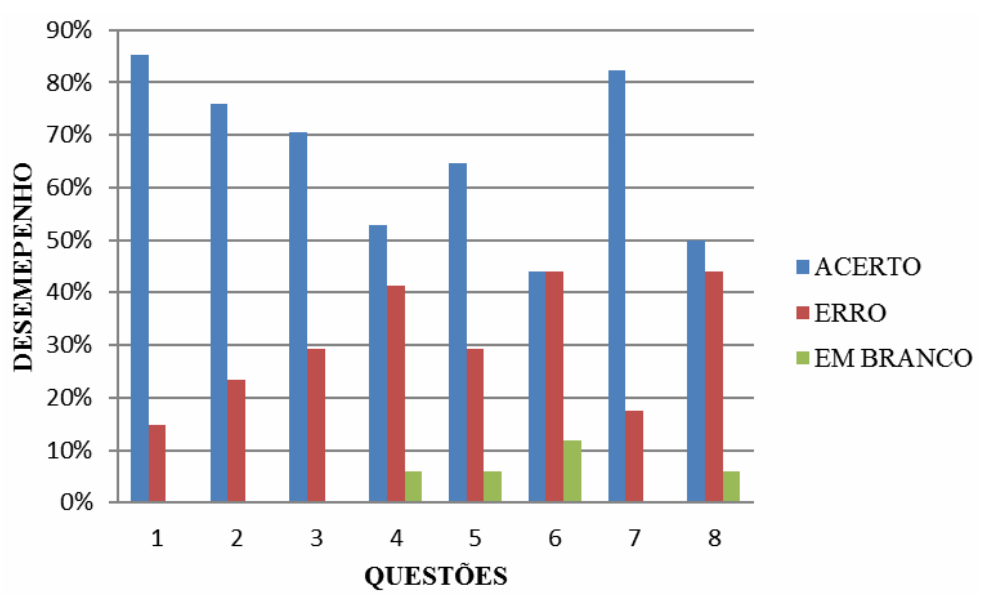

De acordo com Albuquerque e Santos (2008), os resultados esperados ao se utilizar o software GeoGebra nas aulas de geometria dá aos alunos a chance de desenvolver os conhecimentos matemáticos a partir da sua própria intervenção ao construírem seus gráficos, indo além da abstração proporcionada em uma aula exclusivamente expositiva. Nesse contexto, o professor não mais atua como o detentor do saber, mas como um mediador do processo de aprendizagem. Assim,

Ao utilizar o ambiente computacional como meio/instrumento de mediação espera-se motivar o aluno a explorar os conceitos e propriedades da Geometria Plana. Devido às possibilidades oferecidas proporcionar uma aprendizagem significativa dos conteúdos de Matemática, o que elevaria a autoestima do aluno e a melhoria de seu desempenho também em outras disciplinas (ALBUQUERQUE; SANTOS, 2008, p. 23).

Dando segmento a nossa pesquisa e para melhor entendimento da utilização do software e sua contribuição para o aumento de acertos, vamos analisar os itens comparando os resultados do levantamento do conhecimento prévio com os resultados após uso do GeoGebra. Nesse sentido, apresentamos o resultado das questões 1, 2 e 3 no qual trabalhamos o conceito de pontos notáveis do triângulo.

Na questão 1, no momento do levantamento do conhecimento prévio, 50\% dos alunos conseguiram obter a resposta correta na atividade. Após ser trabalhado com o software, este 
percentual teve um aumento perfazendo um total de $85 \%$ dos alunos que responderam a atividade de forma certa, ou seja, 35\% dos alunos que não conseguiram identificar as figuras geométricas com incentro, ortocentro, circuncentro e baricentro no levantamento do conhecimento conseguiram assimilar estes conceitos após uso do GeoGebra.

Para além dos conceitos matemáticos aqui descritos, defendemos a ideia de que o uso da tecnologia da informação e comunicação pode proporcionar ao aluno um aprendizado mais significativo, mais próximo da realidade a partir da simulação de realidades, da concretização das teorias. Segundo os PCN's (1998, p. 44) a utilização desse recurso no processo de ensino e aprendizagem "possibilita o desenvolvimento, nos alunos, de um crescente interesse pela realização de projetos e atividades de investigação e exploração como parte fundamental de sua aprendizagem". Esse resultado pode ser verificado nas atividades posteriores.

Em seguida, na $2^{a}$ questão, houve uma melhora significativa do desempenho, pois apenas $12 \%$ acertaram essa questão (Figura 01) e depois, com o uso do GeoGerbra, $77 \%$ dos alunos conseguiram um bom desempenho, pois no software tem como os alunos visualizar e relacionar os segmentos dados, que de acordo com Oliveira e Tortela (2013) isto ocorre:

\footnotetext{
Devido à praticidade de suas ferramentas e ao seu dinamismo, o GeoGebra também otimiza a visualização e facilita a compreensão e interpretação de conceitos geométricos, em particular, os relacionados ao ensino de pontos notáveis, oportunizando discussões que no papel poderiam até mesmo passar despercebidas, tendo em vista o caráter estático e, por isso, limitado das representações por meio desse recurso. (OLIVEIRA; TORTELA, 2013, p. 26).
}

Com o auxílio do GeoGebra, os alunos tiveram mais chance e possibilidades de encontrar e construir os pontos notáveis do triângulo e, consequentemente, tiveram um bom aprendizado dos conceitos. Nesse sentido, essa assimilação leva a uma apreensão significativa de como aplicar as propriedades em problemas futuros com êxito. Ao contrário, quando trabalhamos apenas com livro didático e o quadro branco, sem demonstrações do que se fala, o conteúdo proposto pelo professor tende a ser decorado pelos alunos apenas para as provas bimestrais.

Posteriormente, na questão 3, em que era necessário, na atividade após uso do GeoGebra, identificar mais de um segmento o acerto foi semelhante ao levantamento do conhecimento prévio, porém, nesse, apenas foi necessário identificar um segmento. Nesse tipo de conhecimento geométrico, solicitado pela questão, 71\% dos alunos não apresentaram dificuldades em resolver os problemas dados.

$\mathrm{Na}$ sequência, apresentamos o resultado obtido na questão 4, cujo objetivo era os alunos resolver os problemas utilizando as propriedades entre segmentos. De acordo com os dados, 53\% dos alunos souberam responder à questão proposta após o uso do GeoGebra. Nesse sentido, o 
desempenho em relação aos acertos pode estar associado ao fato de termos trabalhado com malhas quadriculadas e medidas a partir do uso do GeoGebra assim como a visualização das imagens, pois permitiu aos alunos maior entendimento sobre os casos de semelhança de triângulos e suas propriedades.

Assim, a aplicação em atividades posteriores tenderá a ocorrer de maneira satisfatória, permitindo encontrar os elementos dos triângulos de maneira mais fácil. Nesse contexto, apenas $6 \%$ não entendeu o problema ou não tentaram resolver, antes foi $35 \%$ que deixou a questão em branco. Enquanto $41 \%$ dos alunos ainda têm dificuldades em responder corretamente, observamos que houve uma redução de erros em 7\% quando comparado ao levantamento do conhecimento prévio.

Observando a resolução da questão 5, referente aos problemas que envolvem relações métricas no triângulo retângulo, expressamos os resultados considerado satisfatório, a questão envolvendo o Teorema de Pitágoras obteve um bom índice de acertos: 65\% dos alunos conseguiram acertar a resolução, $29 \%$ erraram e $6 \%$ deixaram em branco.

O aumento do desempenho satisfatório na atividade após uso do GeoGebra foi de $38 \%$ dos alunos. Esse resultado pode ser uma consequência das atividades trabalhadas no laboratório de informática utilizando o GeoGebra em que eles não apenas observavam a construção do Teorema Pitágoras como também iam fazendo usos das ferramentas do software.

Os educandos realizaram uma demonstração do Teorema de forma animada, momento no qual usaram vários recursos como: polígonos, retas, segmentos, interseção de objetos, compasso, circunferência, translação e cores diferenciadas em cada polígono para entenderem a diferença dos catetos e da hipotenusa. Com a demonstração de forma animada conseguiram compreender a demonstração com êxito. Para Souza (2011), um elemento que pode despertar a atenção dos alunos pode está no fato de apresentar antigos conceitos com ferramentas atuais.

Apesar de alguns alunos apresentarem dificuldades na demonstração do teorema com os “arrastes" dos objetos, eles não desistiram e sentiram-se desafiados em aprender o conteúdo e acertar as questões. Nos momentos de dúvidas eles perguntavam uns aos outros ou aos interventores que atuavam também com explanações através de slides para turma, interação que facilitava na resolução dos desafios.

As questões trabalhadas no levantamento do conhecimento prévio e na atividade após uso do GeoGebra foram contextualizadas, pois alguns alunos necessitavam de explanação para a utilização da fórmula. Neste momento $27 \%$ dos alunos no levantamento do conhecimento prévio e $6 \%$ na atividade após uso do GeoGebra tiveram dificuldades em compreender os problemas. Isto, muitas 
vezes, ocorre quando esse conteúdo é trabalhado em sala de aula de maneira não contextualizada, quando as alternativas remetem apenas a encontrar um cateto ou a hipotenusa.

Essa situação nos leva a crer que partindo de um ensino puramente tradicional, apenas pautado na exposição oral, o aluno tende a apenas memorizar as fórmulas matemáticas para fins avaliativos que logo mais serão esquecidas e quando solicitados estes conhecimentos em novas situações, diferentes das rotineiras, são levados ao erro e, consequentemente, desistem de resolver o problema. Mas, as novas tecnologias podem ser utilizadas ao nosso favor e chamar a atenção dos alunos, incentivando-os a partir de um método diferenciado para as aulas em que a utilização dos softwares é um recurso que pode ser inserido quando se pretende estudar o Teorema de Pitágoras.

Vale salientar, porém, que simplesmente utilizar a tecnologia não garante uma aula diferenciada, pois, enquanto meio no processo de ensino e aprendizagem, dependendo da postura do professor, os recursos tecnológicos podem ser utilizados de maneira tradicional. O que queremos elucidar é que a mudança está na concepção do professor e não na utilização do recurso em si.

Em seguida à questão 6, cujo objetivo era trabalhar com trigonometria, os alunos obtiveram um dos melhores resultados na atividade após uso do GeoGebra. De acordo com a Figura 2, mesmo tendo a quantidade de acertos semelhante à quantidade de erros (total de 44\%), o que chama atenção neste caso é que no levantamento do conhecimento prévio $100 \%$ da turma alegou não conseguir resolver o problema porque se tratava de um assunto que estava sendo iniciado o trabalhado em sala de aula e, por isso, não tinham um conhecimento prévio a respeito do mesmo.

Diante dessa afirmação, foi necessária, nas aulas com uso do GeoGebra, a construção de um círculo trigonométrico para que os alunos pudessem compreender as funções do seno, cosseno e da tangente, momento no qual eles receberam uma lista com o passo a passo para criar um círculo trigonométrico. Com esta interferência, procuramos mostrar aos alunos, ainda que rápido, o que vem a ser trigonometria por meio do GeoGebra. Em Zullato (2002, p. 25) vamos encontrar o seguinte esclarecimento "Nos casos em que há resultados duvidosos, por exemplo, a demonstração é um meio indispensável de verificação" ou ainda "A demonstração pode ser vista como um modo de comunicação entre matemáticos profissionais e entre professores e alunos, por exemplo."

Segundo Albuquerque e Santos (2008), os softwares por se apresentarem como um ambiente interativo, no qual os alunos manipulam objetos e seus elementos dinâmicos, permite a construção e investigação de conceitos matemáticos como também a identificação das características das figuras geométricas. Nas atividades os erros cometidos por eles eram em relação ao seno, cosseno e a tangente, que eram confundidos com os lados e não com as razões entre essas medidas. 
Nesse contexto, as discussões com as duplas foram importantes para serem retiradas as dúvidas, assim o resultado da atividade após uso do GeoGebra poderia ser bem mais satisfatório se tivéssemos mais tempo para aprofundamento das questões.

Dando continuidade, o Figura 2 representa o percentual de acertos, erros e em branco da questão 7, cujo objetivo foi estudar o conceito de perímetro. Esse problema foi o de segundo maior percentual de acertos das atividades após uso do GeoGebra no qual $82 \%$ dos alunos conseguiram resolver corretamente o problema e apenas 18\% erraram e nenhum deixou esta atividade em branco.

Nas Figuras 1 e 2, referente ao problema de área de figuras, meta também da questão 8 da atividade realizada pós uso do GeoGebra, os resultados não foram tão satisfatórios quanto o do item anterior. Observamos que o percentual de acertos aumentou porque a quantidade de questões em branco diminuiu já os erros permaneceram na mesma quantidade do levantamento, 44\% não conseguiu resolver corretamente problemas desse tipo. Assim sendo, esta atividade do, pós-uso do software registrou $50 \%$ de acertos e $6 \%$ em branco.

As questões 7 e 8 foram trabalhadas em conjunto com a ajuda do software GeoGebra para os alunos poderem compreender a diferença entre área e perímetro. Nesta atividade, os alunos partiam das definições de cada figura para poderem construir os polígonos corretamente de acordo com as suas características.

Assim, as duplas entre si verificaram se suas respostas estavam coerentes. Feitas essas observações, utilizando o recurso da ferramenta de malha e em cada segmento fixando suas medidas, os alunos utilizaram a ferramenta área e perímetro para seus respectivos cálculos.

Durante as atividades feitas no laboratório nenhum dos grupos deixou de responder às questões, mesmo com a complexidade na construção de polígonos. O que é observado por meio dessas atividades é que as dificuldades residiam mais na interpretação das características das figuras geométricas e na diferenciação das mesmas. A atividade a partir do uso do GeoGebra possibilitou a compreensão de área e perímetro, com uma participação ativa da maioria dos alunos.

Com a redução de questões em branco pela metade, podemos afirmar que a mediação na utilização do GeoGebra facilitou o aprendizado para $12 \%$ da turma e também estimulou o pensamento dos mesmos, levando-os a fazer suposições sobre o conteúdo estudado. Esse resultado remete às reflexões de Parra e Saiz (1996, p. 18) que afirmam que "é preciso educar também no pensar informático, já que não é o mesmo atuar em um mundo sem computadores se no mundo atual, cheio de botões e teclados para apertar e telas para ver, é mais do que de livros, [...]”. Esse fato é bem visto quando, é necessário a interpretação e o raciocínio lógico para realizarem as atividades propostas. 


\section{Análise do questionário}

Além das questões propostas, para entendermos as percepções dos alunos sobre a utilização do GeoGebra nas aulas de Matemática, aplicamos um questionário, no qual buscamos compreender a opinião dos educandos sobre essa prática educativa. Houve uma participação aleatória de 12 alunos; o que corresponde a 35,3\% da turma; destes foram 10 do sexo masculino e 2 do sexo feminino.

Primeiro indagamos os alunos sobre as atividades trabalhadas em matemática a maioria classificaram como boa, porém afirmaram que quando os exercícios são realizados a partir do uso de tecnologia tona-se mais interessante.

Em seguida os alunos disseram que a tecnologia na sala de aula é importante porque eles podem deixar os conteúdos armazenados no computador para consultas posteriores e, quando bem instruídos, podem praticar coisas novas, melhorando, assim, seu desempenho na resolução de problemas, é uma nova forma de aprender geometria. Essas coisas novas podem ser compreendidas como novos conteúdos nas aulas de matemática.

Posteriormente, ainda sobre o uso do GeoGebra, os alunos disseram que essa foi a primeira vez que estavam fazendo uso desta ferramenta na sala de aula. Todos, de forma positiva, disseram que o uso do software deixou as aulas de geometria mais atrativas.

Enquanto as dificuldades encontradas, alguns relataram que não tiveram nenhum problema em relação às ferramentas do GeoGebra; mas suas dificuldades eram em relação ao computador: como salvar, colocar caracteres no seu manuseio. Outros relataram que as suas dificuldades estavam nas construções de ângulos, bissetriz e mediatriz ou quando confundiam segmentos definidos por dois pontos com segmento com o comprimento fixo, ou seja, ferramentas bem parecidas.

Quanto à questão que apresentaram um maior grau de dificuldade, 9 alunos afirmaram que as questões com trigonometria são as mais difíceis de resolver por envolver ângulos e medidas exatas e era o conteúdo que estava sendo abordado nas aulas de matemática em que os mesmos tinham apenas uma pequena noção. 3 alunos acharam que as atividades com os pontos notáveis do triângulo são mais complicadas uma vez que tem que desenhar o ortocentro, incentro e baricentro, principalmente, quando as medidas são dadas.

Quando os alunos foram questionados em relação ao uso do GeoGebra no ensino de Matemática, sua facilitação para a aprendizagem, estes afirmavam ser positivo a integração deste recurso ao processo de ensino-aprendizagem. Consideravam ser mais fácil através dos desenhos entenderem as preposições geometria e assimilar conteúdo exposto pelo professor o qual às vezes não é possível com o caderno e o quadro. 
Verificou-se também, que é bem mais rápido demostrar a diferença entre reta, semirreta, catetos, hipotenusas e as visualizações dos ângulos com o GeoGebra e os polígonos, neste software, tem medidas e retas mais definidas. Muitas vezes os desenhos feitos na lousa pelo professor e no caderno pelo aluno não correspondem à figura correta. Que de acordo com Bennett (2004) apud Oliveira (2013, p. 23),

O uso do GeoGebra pode auxiliar no processo de transformação daquilo que é abstrato para o concreto (visível), pois o ambiente de Geometria Dinâmica encoraja o processo de descobertas e reflete mais de perto a forma como o ensino de matemática é construído: um matemático, inicialmente, visualiza e analisa um problema, fazendo conjecturas antes de realizar provas e demonstrações (BENNETT, 2004 apud OLIVEIRA, 2013. p. 23).

Estas observações nos levantam indícios de que é importante o uso das tecnologias na Educação Matemática, pois elas podem despertar o interesse dos alunos e sua participação passa a ser bem mais proveitosa, deixando as aulas mais atrativas, fazendo com que os alunos não desistam diante do primeiro erro e busquem chegar a uma solução, a interação é maior entre eles, pois, muitas vezes, quem terminava primeiro uma atividade ajudava aos outros colegas de classe.

A descoberta da resolução correta se dá pela facilidade de construir figuras geométricas, além de poder manipular e "arrastar" o que não é permitido no caderno ou na lousa. Afirma-se que desta maneira o conhecimento não é decorado, e sim construído com as ferramentas digitais. Assim, a utilização do laboratório de informática nas aulas de matemática com uso do software GeoGebra é bem mais significativo.

As avaliações com descritores em que envolva o que os alunos apreciam sempre rende bons resultados e a tecnologia faz parte do cotidiano de muitos, o que tem facilitado e aumentado o interesse em aprender. $\mathrm{O}$ grau de concentração é bem maior do que uma aula apenas com livros e quadro e, se bem utilizado, pode, portanto, superar muitas das dificuldades em Matemática.

Os softwares se mostram como aliados para amenizar o baixo rendimento, pois proporcionam uma visualização melhor e mais precisam das figuras, polígonos e sólidos geométricos os quais às vezes não são bem desenhados no caderno e na lousa, fazendo com que o aluno tenha definições erradas e memorização de fórmulas prontas.

A entrada da tecnologia na sala de aula através de softwares permite aos alunos diferenciar e manipular objetos matemáticos, mas ainda existe um número considerável de professores que não utilizam estes softwares. Portanto, é necessária uma sequência de aula bem planejada para que os novos instrumentos educacionais não sejam manipulados com métodos antigos. Segundo Sat (1995, p. 36 apud Zulatto, 2002, p. 6) “assim como um bom livro-texto não é, por si só, garantia de um 
bom curso, também um bom software precisa ser bem explorado por mestres e alunos para dar bons resultados".

Correa reforça esta ideia dizendo:

[...] as inovações tecnológicas não significam inovações pedagógicas. Por meio de recursos considerados inovadores, reproduzem as mesmas atitudes, o mesmo paradigma educacional pelo qual fomos formados. Não basta trocar de metodologia, sem antes de reformular a sua prática, porque senão estaremos repetindo os mesmos erros. Devemos (...) compreender a tecnologia para além do artefato, recuperando sua dimensão humana e social (CORREA, 2002, p. 44).

As atividades rotineiras baseadas em exemplos que deram certo em determinada turma ou região, mas a qual não faz parte de sua cultura e não está relacionada a nada do que possa observar em seu cotidiano, tornam-se conteúdos cansativos e de informações vazias. A utilização de software como recurso didático nestas aulas de matemática pode não dá condições para criar um ambiente de aprendizagem e em consequência os alunos venham a não resolver os problemas solicitados.

Os softwares devem ser utilizados como uma ferramenta didática em suas aulas de matemática permitindo o professor modificar a maneira de planejar as aulas, colocando um novo ritmo e dimensões à tarefa de entender conceitos e códigos que, no discurso de Santos (2009), "As tecnologias informação e comunicação (TIC's) podem favorecer a formação de uma teia entre a escola e o cotidiano, onde o indivíduo e buscar novos caminhos para desenvolver sua compreensão sobre o mundo".

Como ensino de matemática é pautado em descritores com regras e conceitos que não despertam o interesse dos alunos, para Rossini (2008, p. 10) "é preciso que a educação seja mais significativa, mais prazerosa e o que se aborda faça algum sentido para educando, seja do seu interesse, satisfaça suas necessidades biopsicossociais e que o prepare para o mundo de hoje". São grandes as limitações, neste contexto da educação por isso é necessário um ensino-aprendizagem em que a ação educativa complemente os modelos tradicionais e promova um ensino inovador e lúdico diante das possibilidades educacionais.

\section{Conclusões}

Com o uso da ferramenta didática GeoGebra nas aulas de Matemática do ensino fundamental, percebemos que o interesse e a participação em resolver as atividades levadas para sala de aula não foram prejudicadas, mesmo obtendo erros os alunos não desistiam de solucionarem os problemas propostos. Mostraram muito entusiasmo, justificando as respostas encontradas através das imagens. Nesse sentido, o aluno não só pensou o processo de resolução dos problemas como visualizou seus resultados com uso das imagens. 
Pudemos observar que a quantidade de erros e questões em branco teve uma mudança significativa após o uso do GeoGebra. Percebemos que o uso do software na sala de aula aumentou o quantitativo de acertos o que nos dá, a saber, que as dificuldades encontradas no levantamento do conhecimento prévio foram compreendidas.

Trazer estes softwares educacionais para a sala de aula é oportuno porque permite aos alunos entrarem em contato com atividades dinâmicas e diferenciadas que ao mesmo tempo proporciona solucionar exercícios propostos como construir conhecimentos de forma lúdica e produtiva. No caso do software geométrico, é permitido mediar à resolução de problemas geométricos trazidos pelos livros didáticos por meio de uma interação aluno/software em que há manipulação, dando uma sensação dinâmica.

A partir da comprovação de que é possível fazer uso de softwares educativos, neste caso o GeoGebra, como recurso de que dispõe o professor do ensino de matemática, encerramos nossas observações e reflexões evidenciando que é imprescindível o aprofundamento da temática, pois a discussão não se encerra neste trabalho, pelo contrário, ainda há caminhos a serem seguidos e estudados para que ocorra uma mudança considerável no ensino de matemática , assim como, uma quebra do mito de que as aulas de matemática são difíceis e distantes da realidade dos alunos e para que a inserção dos recursos tecnológicos no ambiente educacional possa ser adotada e utilizada continuamente no dia a dia de professores e alunos.

\section{Referências}

ALBUQUERQUE, L.; SANTOS, C. H. O Programa GeoGebra: relato de experiência no ensino de geometria plana de $5^{\mathrm{a}}$ a $8^{\mathrm{a}}$ séries e na socialização com professores da rede de ensino estadual. 2008. Disponível em: 〈http://www.diaadiaeducacao.pr.gov.br/portals/pde/arquivos/1735-6.pdf>. Acesso em: 2 jun. 2015.

ALVES-MAZZOTTI, A. J. Usos e abusos dos estudos de caso. Cadernos de pesquisa, v. 36, n. 129, p. 637-651. 2006. Disponível em: <http://www.scielo.br/pdf/cp/v36n129/a0736129>. Acesso em: 20 fev. 2015.

BELFORT, E. Utilizando o Computador na Capacitação de Professores. In: CARVALHO, L. M.; GUIMARÃES, L.C. (Org.). História e Tecnologia no Ensino da Matemática. Rio de Janeiro: IME-UERJ, cap. 3, p. 39-50, 2002.

\section{BOLGHERONI, W.; SILVEIRA, I. F. Software Livre Aplicado ao Ensino de Geometria e}

Desenho Geométrico. Anais... do XVIII Congresso da SBC. WIE- Workshop sobre Informática na Escola, 12-18 de julho, Belém do Pará-PA, 2008. Disponivel em: <http://ceiesbc.educacao.ws/pub/index.php/wie/article/view/987/97>. Acesso: 13 maio/2014. 
BRASIL. Secretaria de Educação Fundamental. Parâmetros Curriculares nacionais: Matemática/ Secretaria de Educação Fundamental. Brasilia: Mec/ SEF, 1998. 148p.

CORREA, J. Novas Tecnologias da informação e da comunicação: novas: novas estratégias de ensino/aprendizagem. In: COSCARELLI, C. V. (org) Novas Tecnologias, novos textos, novas formas de pensar. Belo Horizonte: Autêntica, p.43-50, 2002.

COSTA, J. W; OLIVEIRA, M. A. M. (orgs.). Novas linguagens e novas tecnologias. Petrópolis: editora vozes, 2004.149p.

OLIVEIRA, C. C.; COSTA, J. W.; MOREIRA, M. Ambientes informatizados de aprendizagem: produção e avaliação de softwares educativo. Campinas: Papirus, 2001.

OLIVEIRA, J. C. R.; TORTOLA, E. O ensino de pontos notáveis por meio do geogebra: uma discussão em um curso de formação continuada. Actas del VII CIBEM, Montevideo/Uruguay. 16 a 20 de setembro de 2013. Disponível em: 〈http://www.cibem7.semur.edu.uy/7/actas/pdfs/1122.pdf>. Acesso: 30 maio. 2015.

PARRA, C. S. I. (org). Didática da matemática: reflexões psicopedagógicas. Porto Alegre: artes Médicas, 1996.

PERNAMBUCO (Estado). Parâmetros para educação básica do Estado de Pernambuco. Parâmetro na sala de aula Matemática Ensino fundamental. Pernambuco: UNDIME-PE. 2013.

ROSSINI, M. A. S. Aprender tem que ser com gosto. 5 ed. Petrópolis, RJ: Vozes, 2008.

SÀ, P. F.; JUCÀ, R. S. Matemática por atividades; experiências didáticas bem - sucedida. Petrópolis, RJ; Vozes, 2014.

SAEPE. Sistema de Avaliação Educacional de Pernambuco. 2013. Disponível em: <www.saepe.caedufjf.net/resultados/resultados-2013/resultados-por-escola〉. Acesso: 15 dez. 2012 SANTOS, N. A. T. L. Sala de informática: ensino e aprendizagem interdisciplinar em uma escola bem sucedida da rede municipal de ensino. 2009. Campo Grande-MS. Disponível em: <http://pead.ucpel.tche.br/revistas/index.php/colabora/article/viewFile/124/108>. Acesso: 10 jul. 2014.

SOUZA, C. F. et al. O software geogebra contextualizando a geometria plana. XIII Conferência interamericana de educação matemática 2011. Disponível em:

<http://cimm.ucr.ac.cr/ocs/index.php/xiii_ciaem/xiii_ciaem/paper/view/1893/0>. Acesso: 5 nov. 2015.

SOUZA, M. H. S. Utilização de softwares no ensino da Geometria. 2011. Disponível em: $<$ http://cmais.com.br/educacao/utilizacao-de-softwares-no-ensino-da-geometria $>$. Acesso em: 10 out. 2014.

ZULATTO, R. B. A. Professores de Matemática que Utilizam Softwares de Geometria Dinâmica: suas características e perspectivas. 2002. 184f. Dissertação (Mestrado em Educação Matemática). Instituto de Geociências e Ciências Exatas, Universidade Estadual Paulista, 2002. 